\section{BMJ Open \\ Respiratory \\ Research}

\title{
The effects of pleural fluid drainage on respiratory function in mechanically ventilated patients after cardiac surgery
}

\author{
Fraser J H Brims, ${ }^{1,2,3}$ Michael G Davies, ${ }^{4}$ Andy Elia, ${ }^{4}$ Mark J D Griffiths ${ }^{4,5}$
}

To cite: Brims FJH, Davies MG, Elia A, et al. The effects of pleural fluid drainage on respiratory function in mechanically ventilated patients after cardiac surgery. BMJ Open Resp Res 2015;2:e000080. doi:10.1136/bmjresp-2015000080

Received 9 February 2015 Revised 10 April 2015 Accepted 13 April 2015

\section{CrossMark}

\begin{abstract}
${ }^{1}$ Department of Respiratory Medicine, Sir Charles Gairdner Hospital, Perth, Western Australia, Australia ${ }^{2}$ Faculty of Medicine, Dentistry and Health Sciences, University of Western Australia, Western Australia, Australia ${ }^{3}$ Institute for Lung Health, Western Australia, Australia ${ }^{4}$ Adult Intensive Care Unit, Royal Brompton Hospital, London, UK

${ }^{5}$ Unit of Critical Care, Royal Brompton Campus, National Heart \& Lung Institute of Imperial College, London, UK
\end{abstract}

Correspondence to Dr Mark JD Griffiths; m.griffiths@imperial.ac.uk

\section{ABSTRACT}

Background: Pleural effusions occur commonly after cardiac surgery and the effects of drainage on gas exchange in this population are not well established. We examined pulmonary function indices following drainage of pleural effusions in cardiac surgery patients.

Methods: We performed a retrospective study examining the effects of pleural fluid drainage on the lung function indices of patients recovering from cardiac surgery requiring mechanical ventilation for more than 7 days. We specifically analysed patients who had pleural fluid removed via an intercostal tube (ICT: drain group) compared with those of a control group (no effusion, no ICT).

Results: In the drain group, 52 ICTs were sited in 45 patients. The mean (SD) volume of fluid drained was 1180 (634) $\mathrm{mL}$. Indices of oxygenation were significantly worse in the drain group compared with controls prior to drainage. The arterial oxygen tension $\left(\mathrm{PaO}_{2}\right) /$ fractional inspired oxygen $\left(\mathrm{FiO}_{2}\right)(\mathrm{P} / \mathrm{F})$ ratio improved on day 1 after ICT placement (mean (SD), day $0: 31.01$ (8.92) vs $37.18(10.7) ; p<0.05)$ and both the $\mathrm{P} / \mathrm{F}$ ratio and oxygenation index (Ol: $\mathrm{kPa} / \mathrm{cm} \mathrm{H}_{2} \mathrm{O}=\mathrm{PaO}_{2} /$ mean airway pressure $\times \mathrm{FiO}_{2}$ ) demonstrated sustained improvement to day 5 (P/F day 5: 39.85 (12.8); OI day $0: 2.88(1.10)$ vs day $5: 4.06(1.73)$; both $p<0.01)$. The drain group patients were more likely to have an improved mode of ventilation on day 1 compared with controls $(p=0.028)$.

Conclusions: Pleural effusion after cardiac surgery may impair oxygenation. Drainage of pleural fluid is associated with a rapid and sustained improvement in oxygenation.

\section{INTRODUCTION}

Pleural effusion is common in patients recovering from cardiac surgery. ${ }^{1-3}$ Large effusions, occupying more than a quarter of the hemithorax, affect approximately $3-10 \%$ of these patients. ${ }^{145}$ Most effusions have no identifiable cause, although surgical practices including the use of internal mammary artery grafts ${ }^{1}{ }^{6}$ and topical hypothermia, ${ }^{7-9}$ with clinical factors such as presence of heart

\section{KEY MESSAGES}

Pleural effusion(s) after cardiac surgery are common.

- This retrospective study demonstrates that drainage of pleural fluid is associated with a rapid and sustained improvement in oxygenation in postsurgical mechanically ventilated patients.

There remains a need, however, for high-quality, controlled studies in this field to inform clinical practice.

failure, arrhythmias and use of anticoagulants, may be risk factors. ${ }^{10}$

Pleural effusions may cause hypoxaemia by creating an intrapulmonary shunt, ${ }^{11}{ }^{12}$ alternatively the cause of the effusion, such as atelectasis, may itself contribute to ventilation/perfusion mismatch. ${ }^{13}$ Experimental studies suggest that the presence of a pleural effusion reduces lung compliance, and there may be an increase in chest wall compliance (reviewed in ref. 14). Large effusions may reduce the patient's tidal volume causing hypercapnia. ${ }^{15}$ The results of small studies carried out on different patient populations have suggested that intercostal tube (ICT) drainage of effusions may improve gas exchange $^{11} \quad 16-22$ and indices of pulmonary function; ${ }^{15} \quad 1923 \quad 24$ however, the effects demonstrated have been modest, variable ${ }^{2125}$ and, to date, not reported in patients following cardiothoracic surgery.

We studied patients requiring a prolonged period of invasive mechanical ventilation after cardiac surgery, to examine the effects of ICT drainage of pleural effusions on indices of pulmonary function.

\section{METHODS}

\section{Patients and data collection}

Data from a consecutive 24-month period were collected retrospectively for patients recovering from cardiac surgery in the adult intensive care unit (AICU) of the Royal 
Brompton Hospital, London, UK, which supports the work of a national referral centre for cardiothoracic surgery and medicine. All data were collected routinely as part of patients' treatment and ongoing care. Because no additional data, or interventions, were collected or performed outside of normal best practice, the Local Regional Ethics Committee deemed that specific ethics approval was not required for this study.

Comprehensive clinical and laboratory data are recorded real time on a computerised system (CareVue, Phillips Medical Systems, Andover, Massachusetts, USA). Data were then accessed using Microsoft Access 2000 (Microsoft Corp, Redmond, Washington, USA). After interrogation of the database for the inclusion criteria, demographic data including date of operation and drain placement, Acute Physiology and Chronic Health Evaluation (APACHE) II score, mode of ventilation, physiological parameters and mortality were recorded. The date, time and side of ICT placement was confirmed by reviewing relevant chest radiographs (WINRAD system, Line Imaging, Atlanta, Georgia, USA).

Patients who had spent more than 7 days on the AICU after surgery with a pleural effusion and ICT insertion were enrolled to a 'drain group', and those with neither ICT nor pleural effusion assigned to a comparison or 'control group'. All patients from both groups had chest radiographs examined to confirm the presence of a pleural effusion and an ipsilateral ICT in the drain group, and absence of effusion in the control group. Patients with postoperative haemothorax or pneumothorax were excluded from the analysis. Data were excluded from patients with no retrievable chest radiograph. Patients otherwise had standard appropriate medical therapy. Serious adverse events following ICT insertion were defined as: significant haemorrhage (that requiring more intervention than the application of local pressure), pneumothorax, infection developing in the pleural space or at the wound site, and malposition.

The decision to place an ICT was not protocol driven, but made depending on the patients' individual clinical and physiological state and requirements. All ICT insertions were carried out under ultrasound guidance using the modified Seldinger technique (12 Fr: Portex Inc, Keene, New Hampshire, USA). Mean values of the physiological parameters were calculated from at least three data sets taken around 8:00. The days were designated 'day 0 ' for the day of ICT insertion in the drain group and day 8 of mechanical ventilation in the control group, and 'days 1-5' for the subsequent days.

\section{Indices of gas exchange}

The arterial oxygen tension $\left(\mathrm{PaO}_{2}\right) /$ fractional inspired oxygen $\left(\mathrm{FiO}_{2}\right)$ ratio $(\mathrm{kPa}: \mathrm{P} / \mathrm{F}$ ratio) is one of the most commonly used and simple measures of oxygenation. It does not however take into account other variables in mechanically ventilated patients that affect gas exchange, for example, the positive end-expiratory pressure (PEEP).
Therefore, the oxygenation index (OI: $\mathrm{kPa} / \mathrm{cm} \mathrm{H}_{2} \mathrm{O}=\mathrm{PaO}_{2}$ / mean airway pressure $\times \mathrm{FiO}_{2}$ ) was used as an additional measure of oxygenation. This version of the OI has been validated as a measure of intrapulmonary shunt in patients undergoing cardiac surgery. ${ }^{26}$ The ventilation index (VI: $\mathrm{cm} \mathrm{H}_{2} \mathrm{O} \mathrm{kPa} / \mathrm{min}=$ peak airway pressure $\times$ respiratory ratexarterial carbon dioxide tension $\left(\mathrm{PaCO}_{2}\right) /$ 1000) was also calculated as a marker of dead-space ventilation. ${ }^{27}$ As the OI and VI require physiological indices (mean and peak airway pressure) that are only available in mechanically ventilated patients, and $\mathrm{PF}$ ratio requires an arterial line, if a patient was weaned from positive pressure ventilation, and/or arterial lines removed, these indices could not be calculated.

\section{Indices of respiratory weaning}

A standardised weaning protocol was not imposed. However, the qualitative step down in respiratory support, which is standard practice in the AICU, was recorded: volume or pressure-controlled mandatory breaths $>$ pressure supported spontaneous breaths $>$ continuous positive airway pressure $>$ spontaneous ventilation without positive pressure.

\section{Data analysis}

Data were analysed using Graph-Pad Prism V.4.00 (GraphPad Software, San Diego, California, USA). All data are expressed as mean and SD. The normality of data distribution was assessed by the Kolmogorov-Smirnov test; categorical data were compared using Fisher's exact test and two conditions were compared using the Student $t$ test. When three or more conditions were compared, one-way analysis of variance with repeated measures was used with Dunnett's multiple comparisons test where appropriate. Statistical significance was defined at the $95 \%$ level.

\section{RESULTS}

During the 24-month study period, 147 patients fulfilled the entry criteria. A total of 20 patients were excluded, leaving 82 patients in the control group and 45 patients (52 events) in the drain group. Seventeen episodes were excluded because data were unavailable on day 1 following weaning from positive pressure mechanical ventilation, and/or the removal of the arterial line. The remaining three exclusions were caused by one haemothorax, one pneumothorax and the other had a large calibre ICT inserted, rather than the smaller $12 \mathrm{Fr}$ drains otherwise used in this study.

The clinical characteristics of the patients studied are shown in table 1 . The patients were predominantly male and over 60 years old, with a preponderance of left-sided effusions. Re-do operations accounted for approximately a third of operations in each group: control 16/45 $(35.5 \%)$, drain 23/82 (28.0\%). Six patients had bilateral effusions, which were drained on consecutive days; entry into the study was after the first drain insertion. Overall, 
Table 1 Baseline patient characteristics

\begin{tabular}{|c|c|c|c|}
\hline & $\begin{array}{l}\text { Control group } \\
\mathrm{n}=82\end{array}$ & $\begin{array}{l}\text { Drain group } \\
n=45\end{array}$ & p Value* \\
\hline Age (years) & $63.63 \pm 13.85$ & $67.2 \pm 11.67$ & 0.193 \\
\hline Male (\%) & 64.6 & 60 & 0.701 \\
\hline APACHE II score & $14.9 \pm 4.28$ & $15.62 \pm 5.39$ & 0.411 \\
\hline Length of AICU stay (days) & $10.94 \pm 14.59$ & $24.58 \pm 26.98$ & $<0.0001$ \\
\hline Mortality 6 months after surgery $n=(\%)$ & $6(7.69)$ & $6(13.33)$ & 0.344 \\
\hline Coronary artery bypass graft $n=(\%)$ & $26(32)$ & $16(36)$ & 0.696 \\
\hline Valve(s) replaced or repaired $n=(\%)$ & $43(56)$ & $23(51)$ & 0.991 \\
\hline Other cardiac surgery $n=(\%)$ & $13(12)$ & $6(13)$ & 0.799 \\
\hline Days from operation to drain insertion & NA & $13.98 \pm 11.59$ & - \\
\hline Left-sided effusion (\%) & NA & $32 / 52(61.5)$ & - \\
\hline Mean total volume of pleural fluid drained $(\mathrm{mL})$ & NA & $1180 \pm 634$ & - \\
\hline $\begin{array}{l}\text { Mean volume of pleural fluid drained in first } 24 \mathrm{~h} \\
\text { following drain insertion }(\mathrm{mL})\end{array}$ & NA & $991 \pm 510$ & - \\
\hline
\end{tabular}

$80.8 \%$ of the total pleural fluid drainage occurred in the first $24 \mathrm{~h}$ after ICT insertion. The only demographic parameter that differed with statistical significance between the groups was mean length of stay on AICU (mean (SD), control 10.9 (14.6) vs drain $24.6 \quad$ (27.0); $\mathrm{p}<0.0001)$. No serious adverse events following ICT insertion were recorded during the study period.

\section{Effect of ICT insertion on oxygenation}

Oxygenation was worse at enrolment in the drain compared with the control group $(\mathrm{P} / \mathrm{F}$ ratio, mean $(\mathrm{SD})$, control 36.21 (11.29) vs drain 31.01 (8.92); $\mathrm{p}=0.002$; OI, control 3.6 (1.75) vs drain 2.88 (1.10); $\mathrm{p}=0.019$; table 2). There was a significant improvement in $\mathrm{P} / \mathrm{F}$ ratio at day 1 compared with day 0 after ICT insertion (95\% CI -11.9 to $-0.66 ; \mathrm{p}<0.05)$, which lasted to day $5(95 \% \mathrm{CI}$ -14.4 to $-3.33 ; \mathrm{p}<0.01$; table 3 and figure $1 \mathrm{~A}$ ). The $\mathrm{OI}$ did not change significantly from day 0 to day 1 , but the improvement comparing day 0 to day 5 following ICT insertion was significant $(95 \%$ CI -1.95 to -0.68 ; $\mathrm{p}<0.01$; table 3 and figure $1 \mathrm{~B})$. In the control group, there was no statistically significant change in $\mathrm{P} / \mathrm{F}$ ratio

Table 2 Baseline indices of gas exchange prior to drainage of pleural effusion

\begin{tabular}{|c|c|c|c|}
\hline & $\begin{array}{l}\text { Control } \\
\text { group }\end{array}$ & $\begin{array}{l}\text { Drain } \\
\text { group }\end{array}$ & $\begin{array}{l}\text { p } \\
\text { Value* }^{*}\end{array}$ \\
\hline $\mathrm{PaO}_{2} / \mathrm{FiO}_{2}$ ratio $(\mathrm{kPa})$ & $\begin{array}{l}36.21 \pm 11.29 \\
N=82\end{array}$ & $\begin{array}{l}31.01 \pm 8.92 \\
N=52\end{array}$ & 0.002 \\
\hline $\begin{array}{l}\text { Oxygenation index } \\
\left(\mathrm{kPa} / \mathrm{cm} \mathrm{H}_{2} \mathrm{O}\right)\end{array}$ & $\begin{array}{l}3.60 \pm 1.75 \\
N=75\end{array}$ & $\begin{array}{l}2.88 \pm 1.10 \\
N=40\end{array}$ & 0.019 \\
\hline $\begin{array}{l}\text { Ventilation index } \\
\left(\mathrm{cm} \mathrm{H}_{2} \mathrm{O} \mathrm{kPa} / \mathrm{min}\right)\end{array}$ & $\begin{array}{l}13.87 \pm 5.38 \\
N=45\end{array}$ & $\begin{array}{l}20.15 \pm 8.85 \\
N=30\end{array}$ & 0.012 \\
\hline
\end{tabular}

or OI between day 0 and day 1 , or day 5 over the study period. Full results for $\mathrm{P} / \mathrm{F}$ ratio, OI and VI are presented in table 3 . There was no correlation between the volume of fluid drained and change in $\mathrm{P} / \mathrm{F}$ ratio and OI over the first $24 \mathrm{~h}$ after drainage $(\mathrm{r}=0.02 ; \mathrm{p}=0.86$ and $\mathrm{r}=0.03 ; \mathrm{p}=0.85$, respectively, by Spearman's correlation).

\section{Effect of intercostal drain insertion on the VI}

The VI of the two groups was significantly different at enrolment (control 13.87 (4.49) vs drain 20.15 (8.85); $\mathrm{p}=0.012$; table 2) with a worse score in the drain group. The VI then fell (improved) in the drain group on day 1 following ICT insertion, although the change was not statistically significant (table 3 and figure 2); the control group VI did not change significantly over the study period. Numbers for calculation of the VI were less than those of the OI because data on the peak airway pressure recorded at the same time as the other indices were more limited.

\section{Effect of intercostal drain insertion on ventilatory weaning}

The drain group were more likely to have an improved mode of ventilation on day 1 compared with controls (24/41 vs 22/61) relative risk (RR) 1.62 (95\% CI 1.06 to 2.48; $\mathrm{p}=0.028$ ), but this was not sustained to day 5 (RR $1.21,95 \%$ CI 0.94 to $1.58 ; \mathrm{p}=0.198$ ). There was no statistically significant difference between the two groups in the numbers of patients that were extubated by day 1 or day 5 .

\section{DISCUSSION}

In this retrospective study of patients requiring prolonged mechanical ventilation after cardiac surgery, we have demonstrated that ultrasound-guided ICT drainage of pleural effusions is associated with a sustained benefit in oxygenation. To our knowledge, this is the first time 
Table 3 Gas exchange indices

\begin{tabular}{|c|c|c|c|c|}
\hline & Day 0 & Day 1 & Day 5 & p Value* \\
\hline \multicolumn{5}{|c|}{$\mathrm{PaO}_{2} / \mathrm{FiO}_{2}$ ratio $(\mathrm{kPa})$} \\
\hline Control & $\begin{array}{l}36.21 \pm 11.29 \\
\mathrm{~N}=82\end{array}$ & $\begin{array}{l}35.56 \pm 11.77 \\
N=82\end{array}$ & $\begin{array}{l}35.16 \pm 11.36 \\
N=75\end{array}$ & 0.653 \\
\hline Drain & $\begin{array}{l}31.01 \pm 8.92 \\
N=52\end{array}$ & $\begin{array}{l}37.18 \pm 10.7 \\
N=52\end{array}$ & $\begin{array}{l}39.85 \pm 12.8 \\
N=38\end{array}$ & $<0.0001$ \\
\hline \multicolumn{5}{|c|}{ Oxygenation index $\left(\mathrm{kPa} / \mathrm{cm} \mathrm{H}_{2} \mathrm{O}\right)$} \\
\hline Control & $\begin{array}{l}3.6 \pm 1.75 \\
N=75\end{array}$ & $\begin{array}{l}3.93 \pm 2.57 \\
\mathrm{~N}=75\end{array}$ & $\begin{array}{l}3.45 \pm 1.53 \\
N=43\end{array}$ & 0.413 \\
\hline Drain & $\begin{array}{l}2.88 \pm 1.10 \\
N=40\end{array}$ & $\begin{array}{l}3.49 \pm 1.73 \\
\mathrm{~N}=40\end{array}$ & $\begin{array}{l}4.06 \pm 1.73 \\
N=29\end{array}$ & $<0.0001$ \\
\hline \multicolumn{5}{|c|}{ Ventilation index $\left(\mathrm{cm} \mathrm{H}_{2} \mathrm{O} / \mathrm{kPa} / \mathrm{min}\right)$} \\
\hline Control & $\begin{array}{l}13.87 \pm 4.49 \\
\mathrm{~N}=45\end{array}$ & $\begin{array}{l}14.26 \pm 4.92 \\
N=45\end{array}$ & $\begin{array}{l}15.46 \pm 4.16 \\
N=37\end{array}$ & 0.298 \\
\hline Drain & $\begin{array}{l}20.15 \pm 8.85 \\
N=30\end{array}$ & $\begin{array}{l}17.39 \pm 7.81 \\
\mathrm{~N}=30\end{array}$ & $\begin{array}{l}17.57 \pm 5.65 \\
N=21\end{array}$ & 0.325 \\
\hline
\end{tabular}

this has been demonstrated in this postcardiac surgery population, despite widespread practice of this procedure in cardiothoracic critical care. These data should act as further proof of concept to inform larger, controlled studies that are still required.

The indices of oxygenation in the drain group were worse than those in the control group at enrolment (table 2). This observation is consistent with the data in patients using the multiple inert gas elimination technique suggesting that large effusions impair ventilationperfusion matching, ${ }^{12}$ increasing intrapulmonary shunt, ${ }^{11}$ and our finding that drainage of the effusion was associated with improved oxygenation (figure 1). In our study, the improvement in oxygenation in the drain
Figure 1 Comparison of the effects of intercostal tube drainage of pleural fluid (drain group: solid bars) and no intervention (control group: open bars) on oxygenation over 6 days in patients recovering from cardiac surgery as assessed by (A) the ratio of arterial oxygen tension $\left(\mathrm{PaO}_{2}\right) /$ fractional inspired oxygen $\left(\mathrm{FiO}_{2}\right)(\mathrm{kPa})$ and $(\mathrm{B})$ oxygenation index $(\mathrm{kPa} /$ $\mathrm{cm} \mathrm{H}_{2} \mathrm{O}=\mathrm{PaO}_{2} /$ mean airway pressure $\times \mathrm{FiO}_{2}$ ). Data are displayed as mean $\pm S D$. Values determined by analysis of variance with multiple comparisons test, compared to day 0 .
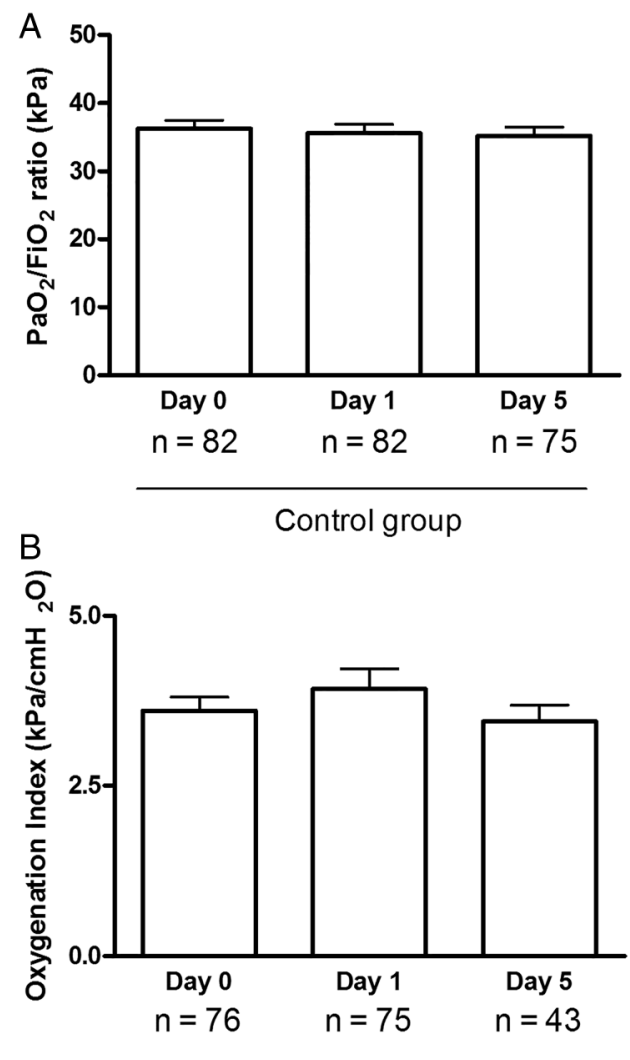

Control group
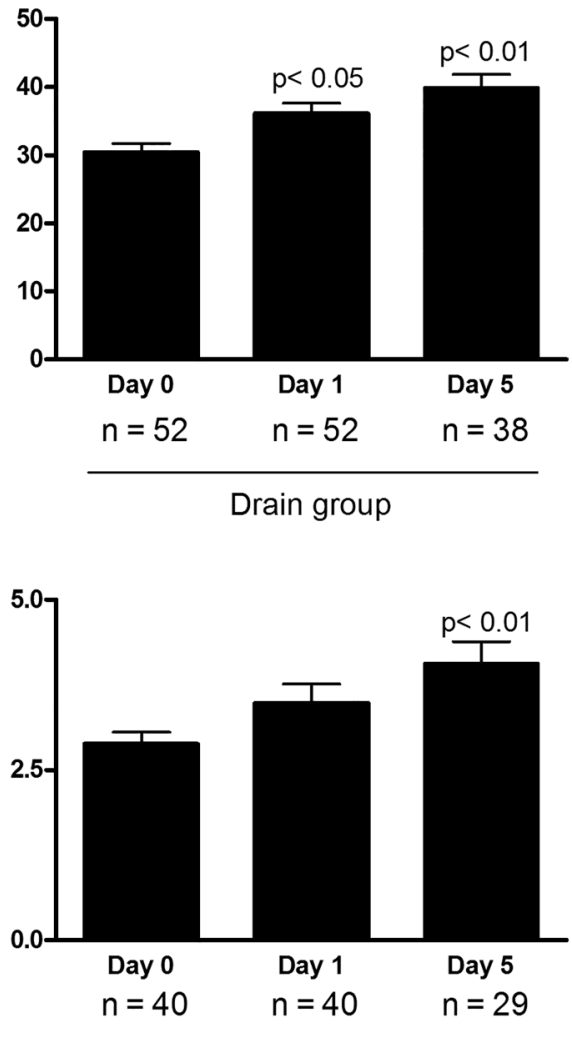

Drain group 

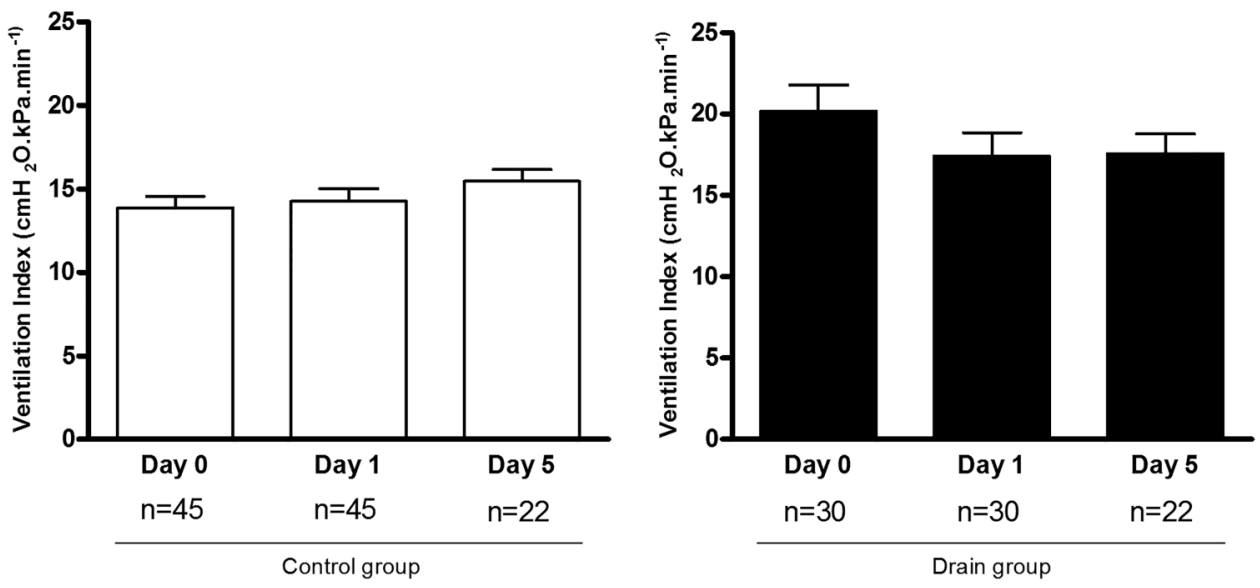

Figure 2 Comparison of the effects of intercostal tube drainage of pleural fluid (drain group: solid bars) and no intervention (control group: open bars) on ventilation index $\left(\mathrm{cm} \mathrm{H}_{2} \mathrm{O} / \mathrm{kPa} / \mathrm{min}=\right.$ peak airway pressurexrespiratory ratexarterial carbon dioxide tension $\left.\left(\mathrm{PaCO}_{2}\right) / 1000\right)$ over 6 days in patients recovering from cardiac surgery. Data displayed as mean $\pm \mathrm{SD}$.

group continued at least up to day 5. This is consistent with other reports ${ }^{28}$ and may reflect delayed lung re-expansion after drainage and possibly with gradual clearance of re-expansion pulmonary oedema. ${ }^{17} 2329$ There are a wide range of potential causes for the presence of a pleural effusion in ICU, ${ }^{30}$ and in this settling, it may be that cardiac function was worse in the drain group, although the data to support this supposition are not available.

Our study is the largest report on a postsurgical ICU population and contributes to a growing literature supporting the notion of improved oxygenation in this population. A previous systematic review examining the effect of pleural fluid drainage in a mixed medicalsurgical population of mechanically ventilated patients $(\mathrm{n}=112)$ describes an improvement in $\mathrm{P} / \mathrm{F}$ ratio, ${ }^{25}$ although the effect was positively skewed by one small (19 patient) uncontrolled study. ${ }^{18}$ The effect in surgical patients is otherwise uncertain with small numbers and heterogeneous results in uncontrolled studies, with different approaches to maintain oxygenation prior to drainage. ${ }^{25}$ Studies in ventilated animals with artificial pleural effusions demonstrate the need for PEEP to prevent cycled recruitment/derecruitment of atelectatic lung (and presumably resultant atelectatrauma), ${ }^{31}$ although the optimal or required level of PEEP in humans is not known. There is a need for high-quality, controlled, prospective studies to establish and delineate any true benefit from this intervention.

A further, recent, small study in a medical ICU demonstrates an early improvement in $\mathrm{P} / \mathrm{F}$ ratio at $3 \mathrm{~h}$ postdrainage, which is sustained at $24 \mathrm{~h}$ postintervention. ${ }^{22}$ Some studies have reported improvements in pulmonary mechanics (peak inspiratory pressure, respiratory rate, plateau pressure and dynamic compliance) within an hour of pleural fluid drainage, ${ }^{11} 1821$ although the same studies do not demonstrate a similar improvement in oxygenation over the same time scale. Reasons for this delayed effect may be as simple as the effusion taking several hours to drain and slow physiological adaptation to the changes in pulmonary mechanics.

In our study, there was no correlation between the physiological indices and the volume of pleural fluid drained, which is consistent with other reports. ${ }^{22}{ }^{25} \mathrm{We}$ were also unable to demonstrate a threshold for the volume of pleural effusion drained that is likely to be associated with clinical benefit. It is possible that by the time an effusion is suspected clinically or on a chest radiograph, and large enough to be safely drained, it may already be over the threshold at which there will be benefit from drainage. Other small studies examining spontaneously breathing medical patients have suggested modest improvements in pulmonary mechanics and oxygenation after ICT insertion. ${ }^{15}{ }^{24}$ In these studies, there was a correlation between the volume of pleural fluid drained and a benefit in the parameters studied. Even if it were possible to demonstrate a threshold of size of pleural effusion above which a patient is likely to benefit, it remains challenging to assess the size of an effusion prior to drainage, especially in recumbent, ventilated patients. ${ }^{32-34}$ Ultrasound, which was used routinely in this study, is the most reliable and safe method of estimation. 35

In this study, there was no significant improvement in VI after ICT placement, although the significant difference in VI at day 0 between the groups was lost at day 1 after drainage. One interpretation of these data is that the known effects of pleural effusion in decreasing lung volumes and compliance ${ }^{36}$ are not readily reversed in this patient group when the fluid is removed. This may be accounted for partially by the fact that the patients were predominantly supine $\left(30^{\circ}\right.$ head up) which would decrease chest wall compliance and that the effusion may have been preceded by and contributed to, by lower lobe atelectasis. ${ }^{37}$ Alternatively, others have observed that with small or moderate sized effusions, as seen in our patients, the lung is displaced rather than 
compressed, ${ }^{38}$ which would predict a modest effect on VI of its removal.

We examined a cohort of patients who had required intensive care for more than 7 days and who were therefore suffering complications following cardiac surgery. This may partly account for the prolonged length of AICU stay demonstrated in the drain group, with the presence of pleural effusion, a non-specific indicator of underlying pulmonary pathology, such as pneumonia. This may be consistent with other reports of postcardiac surgery patients with a pleural effusions having an increased prevalence of postoperative complications. ${ }^{10}$ Care should be taken in interpreting our length of stay data in comparison to others; our unit works as the national referral centre for cardiothoracic surgery, and as such frequently accepts patients that have multiple comorbidity and more complex, challenging operations. We are unable to comment on the incidence of pleural effusion after cardiac surgery or the risk factors for developing a large effusion, although like others, we have noted a preponderance of left-sided effusions. ${ }^{1-3} 37$ This would be expected from the increased incidence of atelectasis and left lower lobe collapse after surgery and the increased likelihood of opening the left pleura to access the left internal mammary artery, if these are indeed important aetiological factors. ${ }^{1} 6133739$

As the calculation of the OI and VI both include physiological indices that can only readily be obtained in mechanically ventilated patients, spontaneously ventilating patients were excluded from analysis of OI and VI. These exclusions introduce a bias that would tend to negate the positive effect of the intervention on gas exchange. Therefore, the beneficial effect of draining large pleural effusions on weaning from mechanical ventilation suggested by our data was probably underestimated. Alternatively, we cannot exclude a non-pulmonary cause for the patient's improvement, for example, drainage of large pleural effusions may significantly improve cardiac output particularly in patients with impaired cardiac function. ${ }^{14} 40$

The most important limitation of this study is that it was performed retrospectively. While our entry criteria defined a control group who were similar to the patients requiring drainage of pleural fluid, the period of data collection was also different between the two groups, being from day 7 after the operation in the control group and from the day of ICT insertion in the drain group (median 10 days). Another limitation of the study was that neither the decision to insert an ICT nor the ventilatory weaning was protocol driven. Additionally, we cannot completely exclude the presence of undrained effusions in the control population. While none were evident when the chest radiographs were reviewed, we accept that due to the sensitivity of chest radiography for identifying pleural effusions in this population $(\approx 80 \%),{ }^{41}$ it is possible that small effusions may not have been identified, although it is unlikely that a moderate or large effusion will have been missed.
Furthermore, it is possible that the patient's apparent readiness to step down in respiratory support could have influenced the decision to drain the pleural fluid. Finally, we have not accounted for possible differences in fluid balance and/or pharmacological therapy (eg, diuretic use) that patients may have had.

In summary, our data provide novel physiological evidence to support the current practice in cardiothoracic critical care of draining large pleural effusions in patients requiring prolonged mechanical ventilation after cardiac surgery, possibly as a means of improving oxygenation and facilitating respiratory weaning. Considering the limitations of this report, further randomised controlled studies are required to examine if the drainage of pleural effusions facilitates weaning from mechanical ventilation in the cardiothoracic and general ICU population, and to attempt to identify a threshold of effusion size that would predict benefit from drainage.

Contributors FJHB was involved in data collection, analysis and write up. $M G D$ was involved in data collection and write up. AE was involved in data collection. MJDG was involved in data analysis and write up.

Competing interests None declared.

Provenance and peer review Not commissioned; externally peer reviewed.

Data sharing statements No additional data are available.

Open Access This is an Open Access article distributed in accordance with the Creative Commons Attribution Non Commercial (CC BY-NC 4.0) license, which permits others to distribute, remix, adapt, build upon this work noncommercially, and license their derivative works on different terms, provided the original work is properly cited and the use is non-commercial. See: http:// creativecommons.org/licenses/by-nc/4.0/

\section{REFERENCES}

1. Light RW, Rogers JT, Moyers JP, et al. Prevalence and clinical course of pleural effusions at 30 days after coronary artery and cardiac surgery. Am J Respir Crit Care Med 2002;166(12 Pt 1): 1567-71.

2. Light RW, Rogers JT, Cheng D, et al. Large pleural effusions occurring after coronary artery bypass grafting. Cardiovascular surgery associates, PC. Ann Intern Med 1999;130:891-6.

3. Piccoli $M$, Trambaiolo $P$, Salustri $A$, et al. Bedside diagnosis and follow-up of patients with pleural effusion by a hand-carried ultrasound device early after cardiac surgery. Chest 2005;128:3413-20.

4. Peng MC, Hou CJ, Li JY, et al. Prevalence of symptomatic large pleural effusions first diagnosed more than 30 days after coronary artery bypass graft surgery. Respirology 2007;12:122-6.

5. Lancey RA, Gaca C, Vander Salm TJ. The use of smaller, more flexible chest drains following open heart surgery: an initial evaluation. Chest 2001;119:19-24.

6. Landymore RW, Howell F. Pulmonary complications following myocardial revascularization with the internal mammary artery graft. Eur J Cardiothorac Surg 1990;4:156-61.

7. Nikas DJ, Ramadan FM, Elefteriades JA. Topical hypothermia: ineffective and deleterious as adjunct to cardioplegia for myocardial protection. Ann Thorac Surg 1998;65:28-31.

8. Allen BS, Buckberg GD, Rosenkranz ER, et al. Topical cardiac hypothermia in patients with coronary disease. An unnecessary adjunct to cardioplegic protection and cause of pulmonary morbidity. $J$ Thorac Cardiovasc Surg 1992;104:626-31.

9. Efthimiou J, Butler J, Woodham C, et al. Diaphragm paralysis following cardiac surgery: role of phrenic nerve cold injury. Ann Thorac Surg 1991;52:1005-8.

10. Labidi M, Baillot R, Dionne B, et al. Pleural effusions following cardiac surgery: prevalence, risk factors, and clinical features. Chest 2009;136:1604-11.

11. Ahmed SH, Ouzounian SP, Dirusso S, et al. Hemodynamic and pulmonary changes after drainage of significant pleural effusions in 
critically ill, mechanically ventilated surgical patients. $J$ Trauma 2004:57:1184-8.

12. Agusti AG, Cardus J, Roca J, et al. Ventilation-perfusion mismatch in patients with pleural effusion: effects of thoracentesis. $A m J$ Respir Crit Care Med 1997;156(4 Pt 1):1205-9.

13. Daganou M, Dimopoulou I, Michalopoulos N, et al. Respiratory complications after coronary artery bypass surgery with unilateral or bilateral internal mammary artery grafting. Chest 1998;113:1285-9.

14. Graf J. Pleural effusion in the mechanically ventilated patient. Curr Opin Crit Care 2009:15:10-17.

15. Light RW, Stansbury DW, Brown SE. The relationship between pleural pressures and changes in pulmonary function after therapeutic thoracentesis. Am Rev Respir Dis 1986;133:658-61.

16. Roch $A$, Bojan $M$, Michelet $P$, et al. Usefulness of ultrasonography in predicting pleural effusions $>500 \mathrm{~mL}$ in patients receiving mechanical ventilation. Chest 2005;127:224-32.

17. Perpina M, Benlloch E, Marco V, et al. Effect of thoracentesis on pulmonary gas exchange. Thorax 1983;38:747-50.

18. Talmor M, Hydo L, Gershenwald JG, et al. Beneficial effects of chest tube drainage of pleural effusion in acute respiratory failure refractory to positive end-expiratory pressure ventilation. Surgery 1998;123:137-43.

19. Wang JS, Tseng $\mathrm{CH}$. Changes in pulmonary mechanics and gas exchange after thoracentesis on patients with inversion of a hemidiaphragm secondary to large pleural effusion. Chest 1995;107:1610-14.

20. De Waele JJ, Hoste E, Benoit D, et al. The effect of tube thoracostomy on oxygenation in ICU patients. J Intensive Care Med 2003;18:100-4.

21. Doelken P, Abreu R, Sahn SA, et al. Effect of thoracentesis on respiratory mechanics and gas exchange in the patient receiving mechanical ventilation. Chest 2006;130:1354-61.

22. Razazi K, Thille AW, Carteaux G, et al. Effects of pleural effusion drainage on oxygenation, respiratory mechanics, and hemodynamics in mechanically ventilated patients. Ann Am Thorac Soc 2014;11:1018-24.

23. Brown NE, Zamel N, Aberman A. Changes in pulmonary mechanics and gas exchange following thoracocentesis. Chest 1978;74:540-2.

24. Zerahn B, Jensen BV, Olsen F, et al. The effect of thoracentesis on lung function and transthoracic electrical bioimpedance. Respir Med 1999;93:196-201.

25. Goligher EC, Leis JA, Fowler RA, et al. Utility and safety of draining pleural effusions in mechanically ventilated patients: a systematic review and meta-analysis. Crit Care 2011;15:R46.
26. El-Khatib MF, Jamaleddine GW. A new oxygenation index for reflecting intrapulmonary shunting in patients undergoing open-heart surgery. Chest 2004;125:592-6.

27. Paret G, Ziv T, Barzilai A, et al. Ventilation index and outcome in children with acute respiratory distress syndrome. Pediatr Pulmonol 1998;26:125-8.

28. Walden AP, Garrard CS, Salmon J. Sustained effects of thoracocentesis on oxygenation in mechanically ventilated patients. Respirology 2010;15:986-92.

29. Trapnell DH, Thurston JG. Unilateral pulmonary oedema after pleural aspiration. Lancet 1970;1:1367-9.

30. Walden AP, Jones QC, Matsa R, et al. Pleural effusions on the intensive care unit; hidden morbidity with therapeutic potential. Respirology 2013;18:246-54.

31. Graf J, Formenti P, Santos A, et al. Pleural effusion complicates monitoring of respiratory mechanics. Crit Care Med 2011;39:2294-9.

32. Schafer C, Sokiranski R, Bartzsch OM, et al. [Diagnosis of pleural effusion in intensive care patients with supine digital thoracic imaging. A study of CT validated cases]. Anasthesiol Intensivmed Notfallmed Schmerzther 1997;32:109-14.

33. Muller NL. Imaging of the pleura. Radiology 1993;186:297-309.

34. Mann $\mathrm{H}$. Common errors in evaluating chest radiographs. Postgrad Med 1990;87:275-8, 81-2.

35. Balik M, Plasil P, Waldauf $P$, et al. Ultrasound estimation of volume of pleural fluid in mechanically ventilated patients. Intensive Care Med 2006;32:318-21.

36. Mitrouska I, Klimathianaki M, Siafakas NM. Effects of pleural effusion on respiratory function. Can Respir J 2004;11:499-503.

37. Peng MJ, Vargas FS, Cukier A, et al. Postoperative pleural changes after coronary revascularization. Comparison between saphenous vein and internal mammary artery grafting. Chest 1992;101:327-30

38. Anthonisen NR, Martin RR. Regional lung function in pleural effusion. Am Rev Respir Dis 1977;116:201-7.

39. Vargas FS, Cukier A, Terra-Filho M, et al. Relationship between pleural changes after myocardial revascularization and pulmonary mechanics. Chest 1992;102:1333-6.

40. Estenne M, Yernault JC, De Troyer A. Mechanism of relief of dyspnea after thoracocentesis in patients with large pleural effusions. Am J Med 1983;74:813-19.

41. Emamian SA, Kaasbol MA, Olsen JF, et al. Accuracy of the diagnosis of pleural effusion on supine chest X-ray. Eur Radiol 1997;7:57-60 